\title{
DITADURA E VIOLÊNCIA EM ZERO, DE IGNÁCIO LOYOLA BRANDÃO: A LITERATURA COMO RESISTÊNCIA AO SILENCIAMENTO
}

Carla Lavorati ${ }^{1}$

\begin{abstract}
Resumo: Zero, romance de Ignácio Loyola Brandão, é a representação ficcional de um território subdesenvolvido que passa por um período ditatorial. O personagem principal José, como os demais integrantes do enredo, vive num contexto de insegurança eminente, onde os direitos humanos estão em suspenso. Sem a utilização de uma organização linear, o romance se desenvolve numa estrutura narrativa que remete à própria alienação e ao caos do período. Nesse sentido, o objetivo da pesquisa é observar como o romance representa esteticamente períodos violentos e coercitivos, numa análise que considera a elaboração de Zero como uma postura ética do autor frente ao silenciamento imposto às diferentes formas de expressão.
\end{abstract}

Palavras chave: Ditadura. Censura. Resistência.

\begin{abstract}
Zero, a novel by Ignacio Loyola Brandão, is the fictional representation of an underdeveloped country undergoing a dictatorial period. The main character Joseph, like the other members of the plot, experience the lack of eminent insecurity, where human rights are suspended. Without the use of a linear organization, the novel develops a narrative structure that refers to own alienation and chaos of the period. In this sense, the objective of the research is to see how the novel is aesthetically periods violent and coercive, an analysis that considers the development of Zero as an ethical stance of the author against the silencing imposed on different forms of expression.
\end{abstract}

Keywords: Dictatorship. Censorship. Resistance.

\section{INTRODUÇÃO}

O processo de construção do romance Zero (2001), de Ignácio Loyola Brandão, está intimamente relacionado com o contexto do regime militar brasileiro e com o trabalho jornalístico do autor, no periódico carioca "Última Hora". Atividade que desempenhou de 1964 a 1973 e que o colocou em contato direto com a constante silenciamento imposto aos meios de comunicação. Portanto, Zero é uma forma de "resposta" à censura e ao volume crescente de material jornalístico proibido de circular; e que serviram,

\footnotetext{
${ }^{1}$ Doutoranda em Estudos Literários no Programa de Pós-Graduação em Letras na UFSM. Bolsista Capes, orientada pela Prof. ${ }^{\text {a }}$ Dr. ${ }^{\text {a }}$ Rosani Ketzer Umbach. E-mail: carlalavorati@hotmail.com
} 
posteriormente, como fonte de inspiração para o autor na elaboração do romance, que foi publicado primeiramente em 1974, numa edição italiana.

Ignácio Loyola Brandão constrói um texto verossímil, sensível ao contexto histórico que viveu, conseguido captar e transformar em material estético a atmosfera caótica e violenta do período. Ou seja, a partir de registros factuais, o autor elabora um romance de estrutura pouco convencional, com inovações textuais e formais, no qual a subversão da narrativa linear, da composição fragmentada e do jogo arbitrário da linguagem metaforiza a situação de coerção política e alienação de um território subdesenvolvido e sob regime ditatorial. Recortes de jornais, frases de banheiros, desenhos, rabiscos, letras de música, poemas, gráficos, que combinados contam a história do personagem central do romance, José, mas também, na expressão do narrador, de toda a "América Latíndia", assolada por muitos atrasos de ordem política, econômica e cultural.

O objetivo dessa pesquisa, nesse sentido, é observar como tanto o aspecto formal de organização do romance como o seu conteúdo contribuem para a representação de facetas de períodos violentos e coercitivos, contribuindo para o que consideramos uma atitude de resistência e uma postura ética do autor frente ao silenciamento imposto às diferentes formas de expressão.

\section{ROMANCE, RESISTÊNCIA, ÉTICA}

Para Auerbach (1971), o romance se transforma pela própria relação que sua forma estética mantém com a sociedade, "Tudo é, portanto, uma questão da posição do escritor diante da realidade do mundo que representa" (Auerbach, 1971, p. 470), nesse sentido é importante refletir sobre como o contexto histórico coercitivo da ditadura militar influenciou a produção do romance Zero e observar como essas marcas são manifestadas no seu conteúdo e na sua forma estética.

A ditadura militar ficou registrada na história do Brasil como um período violento, no qual os militares - após um golpe que afastou os civis do comando - governaram de modo autoritário, cometendo diferentes formas de violência e 
crimes pela manutenção do poder. Sobre a relação entre violência, sociedade e História, Umbach (2011) salienta: "A História brasileira é intensamente caracterizada pela presença de violência em processos sociais. [...] Ela tem uma função propriamente constitutiva: ela define condições de relacionamento público e privado, organiza instituições e estabelece papéis sociais" (Umbach, 2011, p. 147-148). Portanto, esse contexto de violência estabelecido com o golpe militar afeta diferentes dimensões da configuração social e da convivência entre os indivíduos, criando um clima de tensão e insegurança que foi usado a favor da manutenção da ditadura.

Nos jornais se acumulavam materiais proibidos pelos agentes de controle do governo, principalmente nos veículos de comunicação que não eram simpáticos ao regime vigente. Assim, com a crescente fiscalização, controle e censura da veiculação de informações e opiniões, os meios de comunicação que não apoiavam a ditadura encontravam cada vez mais entraves para a livre expressão. A literatura nesse período passa a ser um terreno explorado por muitos escritores, e o jornalismo que já mantinha uma íntima relação com o literário, dilui ainda mais suas fronteiras. Jornalistas, tal qual Ignácio Loyola Brandão, transitaram entre esses dois "mundos" de forma magistral, encontrando no espaço ficcional as possibilidades de continuar escrevendo, comunicando e transfigurando o real, pois, a literatura, nas palavras do próprio escritor "[...] ajudou a driblar o amordaçamento e o silêncio. [...] Nós estamos aqui para contar histórias. Não se pode esquecer que literatura é também contar histórias" (Brandão apud Naxara; Vieira, 2011, p. 213).

Nesse sentido, o campo do literário era encarado como um espaço mais favorável à liberdade de expressão, por sofrer uma censura menos rigorosa, visto que era um produto menos acessível às massas. Os romances, circunscritos ainda a elite leitora, não tinham o mesmo alcance e popularização dos meios de comunicação de massa, como a televisão, rádio ou jornal impresso. Assim, a literatura e as possibilidades estéticas da sua linguagem são utilizadas por muitos escritores na construção de uma representação verossímil da realidade, pois "Se nos jornais e meios de comunicação de 
massa a informação era controlada, cabia à literatura exercer uma função jornalística" (Sussekind, 2004, p. 18), tal qual acontece no romance Zero.

O romance inicia como uma série de fragmentos sobre um continente intitulado "América Latíndia" e encaminha-se para a "retratação" de um período conturbado, de medo e violência, típico ao contexto histórico brasileiro da ditadura militar: "Com a repressão que anda por aí, ninguém quer sair de casa, as ruas são vazias [...]" (Brandão, 2001, p. 19). Os ambientes onde se desenrolam a maior parte dos acontecimentos é o subúrbio; e a classe pobre de indivíduos, alienados e manipulados, é retratada sem rodeios:

[...] As filas no serviço social, crescendo. Briga todas as noites diante dos albergues, debaixo dos viadutos, pontes, nas portas de prédio, portas de igreja[...] Mendigos, vagabundos, desempregados, hordas revirando os lixos da cidade, de todas as cidades. As casas invadidas, ladrões presos ao roubar despensas, armazéns e supermercados protegidos por contingentes policiais. Todo mundo querendo ir para a cadeia onde, ao menos, não se morre de fome. (Brandão, 2001, p. 143)

Desse modo, é possível observar que a denúncia social está presente em vários momentos do texto, como nas descrições do narrador sobre as mazelas sociais que infligem à população; "A massa de desempregados passou para a cidade. Pediam esmolas nos viadutos, portas de igrejas, praças, cinemas. A polícia vinha, prendia, batia. Corpos aleijados foram encontrados nos rios. Os diferentes, apavorados, não sabiam a quem recorrer. Nem tinham a quem." (Brandão, 2001, p.173). Assim, analisamos a narrativa e o narrador de Zero sob as luzes de sua própria historicidade, que foi o período de violência, controle e cerceamento de liberdade comum a regimes políticos autoritários. Portanto, tanto o conteúdo do enredo como sua organização estética mantém relação com um período no qual ao cidadão não era assegurada muitas certezas. Assim, no romance, não encontramos uma postura narrativa que pretenda dar conta de explicar a situação, numa organização linear dos fatos, mas sim um narrador que acima de tudo expõem as contradições da realidade, num modelo estético provocador. Sob essa perspectiva, retomamos Adorno (2003), que diz que no século XX, não é mais "possível" - principalmente após eventos traumáticos, governos ditatoriais, destruição em massa - construir, sem soar anacrônico, uma narrativa com um 
narrador que se posicione como um observador onisciente e que organize a narrativa de modo organizado e claro, pretendendo uma representação e um narrador que mantenha a ilusão de conhecedor e entendedor da realidade. $\mathrm{O}$ indivíduo - inserido num contexto de insegurança e de desconfianças em relação às narrativas totalizantes - não consegue empreender um sentido seguro para a realidade circundante, o que impulsiona o mal estar e mesmo a crise existencial que segue períodos traumáticos.

Dessa forma, torna-se comum a construção de narradores que, afetados pela desconfiança da linguagem e do próprio limite de conhecimento de si mesmo e das coisas, reforçam aspectos de subjetividade e consciência dos limites da representação. O romance Zero também problematiza a transparência da linguagem, a organização linear da narrativa e a onisciência do narrador, o que foi salientado pelo próprio autor em entrevista, que diz: "[...] eu não queria uma estrutura convencional, não poderia ser um livro com começo, meio e fim, explicando o personagem. Pô! O mundo não é esse, o mundo é outro" (Brandão apud Naxara; Vieira, 2011, p. 212).

Assim, a literatura expande as possibilidades de "retratar" o que 0 jornalismo periódico era proibido de expressar. Nesse sentido, podemos relacionar o fortalecimento e importância do romance diante do cenário de silenciamento da grande imprensa, pela possibilidade potencializada pela literatura de representar o proibido, o "irrepresentável”, o que não podia ser trazido a baila pelos demais meios de comunicação, como sugere Cosson (2001), "[...] à literatura da época coube, então, o papel de resistir politicamente às arbitrariedades dessa censura nos jornais e nos outros meios de comunicação; denunciando e revelando as verdades omitidas no silêncio, a história mascarada pela versão oficial” (Cosson, 2001, p.16).

Nesse sentido, em Zero é possível encontrar várias referências à violência e a sua relação com a ditadura que podem ser exemplificadas por trechos como: "Até então, lembra, bater, prender, era coisa comum. Mas a gente não tinha começado a viver está época de mortes, fuzilamentos, torturas desaparecimentos" (Brandão, 2001, p. 161). No trecho seguinte, ocorre a representação de um momento extremo de violação dos direitos humanos:a 
descrição de uma cena de tortura. Os abusos de poder são expostos em vários momentos do texto. Observe:

Não sei que horas eram, vieram me buscar [...] comunista filho da puta, conta dos aparelhos, me dá os endereços... Os fios no meu saco, nas plantas dos pés, fale, conta merdinhadebosta. E agora você vai saber porque me chamam de João Bonzinho disse o coronel enquanto enfiava um fio no canal de minha uretra e ligava o fio direto na tomada e eu sumia no mundo, com tanta dor que nem sentia dor...E o João Bonzinho enfiou um bastão no meu rabo e ligou no magneto e girou a manivela e me caguei todo, a bosta escorreu pelas minhas pernas, eles morreram de rir e disseram que eu devia comer a bosta no chão porque tinha sujado a sala toda e o general comandante não gostava de sala suja... lambe o chão merda de comunista, bandido do caralho, lambe com a língua... Eu comia aquela comida que estava no chão e que já tinha passado dentro de mim e prenderam uns ganchos dentados dentro das minhas orelhas e apertavam apertaram até que a orelha direita foi cortada e eles jogaram no meio da bosta e do mijo e mandaram eu comer feijoada e o mundo sumiu de novo... acorda aí que o interrogatório vai recomeçar... dormi, acordei, dormi, acordei, pau-de-arara, desmaiei, choque, dorme dez minutos, acorda, dorme-acorda-dorme. (Brandão, 2001, p. 288)

A ironia é outra característica forte de Zero e pode ser encontrada em vários momentos, como no seguinte trecho intitulado "Uma curta visita social":

\begin{abstract}
Bom dia, minha senhora. Sou da Polícia Política. Aqui está um cartão. A senhora e seu marido devem preenchê-lo. Coloquem duas fotos $3 \times 4$. Neste saquinho plástico, vocês devem colocar uma cópia da chave de sua casa. Este envelope pardo contém uma Ordem Judicial para que a Polícia entre legalmente na sua casa, a qualquer momento. A senhora deve guardá-la cuidadosamente. Quando um de nossos agentes precisar entrar aqui, baterá, pedirá o mandado e só depois entrará. Obrigado. Ah, se a senhora perder o mandato levará três meses de prisão, antes de obter a segunda via. Passe bem, minha senhora e meus respeitos ao seu marido. Louvado seja. (Brandão, 2001, p. 162)
\end{abstract}

O fragmento acima metaforiza os absurdos ocorridos durante o regime, levando ao extremo uma determinada situação que tem como personagens funcionários do governo. Essa situação, mesmo que hipotética utiliza a sátira para a construção crítica aos abusos de poder. No entanto, as objeções não se limitam aos políticos. Elas vão mais além, com trechos criticando outras esferas de manipulação social, como a da igreja.

Em Zero são potencializados sentidos, sujeitos, histórias proibidas - a maioria delas chegaram até o autor em seu trabalho como periodista e foram proibidas de divulgação - portanto, pelas possibilidades do ficcional, o autor 
encontra chance de (re)contá-las de alguma forma. E, assim, podemos nos referir ainda às relações estabelecidas entre o romance e a memória, pois a gênese do romance advém justamente do acúmulo de arquivos históricos/memorialísticos: "Passado que já nos chega como memória fragmentada, porém impregnada de sua carga simbólica e afetiva. Loyola Brandão tece fios entre diversas lembranças, deixando pistas, sinais, indícios de memórias [...] Literatura que constrói memória" (Naxara; Vieira, 2011, p. 209).

Em entrevista, o autor confirma a importância dos documentos que recolheu ao longo do seu trabalho e que compõem, de alguma forma, o conteúdo do romance, "Então, os depoimentos de torturas que existem dentro de Zero são absolutamente reais - com os nomes mudados, porque eu não podia denunciar as pessoas, nem sei se entre eles alguns já tinham sido mortos, desaparecidos" (Brandão apud Naxara; Vieira,2011, p. 211).

A construção da narrativa de Zero, tal qual declarou o autor, foi alicerçada em um grande volume de arquivos. Documentos que, (re) significados ficcionalmente, mobilizam memórias de acontecimentos históricos. $\mathrm{E}$, nesse caso, as memórias atualizadas no romance, mesmo que indiretas e fragmentadas, compõem vestígios do passado, marcas da violência e censura do período ditatorial brasileiro. Assim, o narrador direciona suas reflexões para um passado comum e a literatura, muitas vezes, funciona como alternativa para "iluminar" veredas ainda obscuras da História oficial. Nesse sentido, para Gagnebin (1998), na dinâmica da memória estão em tensão a ausência e a presença. Sua riqueza e sua fragilidade residem nessa dicotomia, que só remete as coisas na medida em que confirmam a falta do objeto real que representam. Nesse sentido, a representação liga-se tanto à ausência como à tentativa de presentificação. Temos, portanto, em todo processo de "recuperação" de memória e mesmo de qualquer representação do real as sombras da ausência e do passado. Portanto, a memória é tanto um espaço simbólico, de luta pelo controle do discurso e do saber, como espaço fronteiriço, de cruzamento entre individual e coletivo. A memória e a identidade são, portanto, negociadas, pois estão longe de se constituírem como essência individual ou de grupo. E sendo elas construídas, toda a documentação que as 
sustentam também o são. Assim, refletir sobre o funcionamento da memória deve ser um trabalho que leve em consideração as próprias distorções inerentes a sua dinâmica.

Portanto, não podemos pensar a memória e os registros da História como um reservatório de sentido homogêneo e plano, mas sim um espaço de falhas, esquecimentos, deslocamentos, regulação e repetição, no qual ressoa as formações discursivas e as ideologias do sujeito. E nesse sentido, podemos pensar na ocorrência de um jogo de forças que tanto serve para regularizar e estabilizar como desestabilizar sentidos. E a memória, assim, cumpre um duplo papel: o da lembrança e o do esquecimento. A memória é, portanto, um fato social e de significação. $E$ as imagens, nesse sentido, também são atravessadas por ela, recuperando sentidos e (re) significando-os pelas relações que estabelece com a exterioridade. E a literatura, como se refere Ignácio Loyola Brandão: "[...] buscando a memória, buscando as lembranças e retratando o cotidiano, acaba fornecendo os elementos de que se precisa e que são necessários para entender como é que as coisas vieram a acontecer" (Brandão apud Naxara; Vieira, 2011, p. 217).

Dessa forma, o personagem principal, José, é apresentado ao leitor como apenas uma pequena parte do universo, uma pequena parcela de um todo complexo. Essa perspectiva é evidenciada no início do romance, quando o narrador apresenta o protagonista relacionando-o e contrapondo-o a demais características e informações sobre o universo. A descrição do personagem é construída de forma realista, através de uma linguagem que o humaniza e que o deixa longe de qualquer imagem de herói: "Ao contrário, é um infra-herói e passa despercebido, inatacado, desprezado" (Brandão, 2001, p.222). O que encontramos linha após linha é a representação de um homem comum:

José mata ratos num cinema poeira. É um homem comum, 28 anos, que come, dorme, mija, anda, corre, ri, chora, trepa, enxerga bem dos dois olhos, mas toma Melhoral, lê regularmente livros e jornais, vai ao cinema sempre, não usa relógio nem sapato de amarrar, é solteiro e manca um pouco, quando tem emoção forte, boa ou ruim. (Brandão, 2001, p.15)

José assume a função de representar uma coletividade, de identificar-se com a maioria. Essas situações figuram-se dentro de uma realidade possível 
apoiando-se na verossimilhança, na fundamentação do real, ou seja, a inspiração é a vida que acontece a cada dia, com seus dilemas e contratempos. Durante o desenrolar da narrativa ocorrem muitas mudanças com o personagem, sua vida, suas responsabilidades, seu modo de pensar. Essa evolução acompanha os acontecimentos sociais e os problemas da época. José se adapta, se revolta, se arrepende, se confunde, foge, enfrenta, é bom, é ruim: "Eu queria viver louco irremediável, sem ligar para a minha vida, viver sem parar, morrer de tanto viver, não levar essa vida que levo, deslizando, sem fazer nada, sem saber o que sonhei um dia, se sonhei, nem sei o que quero" (Brandão, 2001, p. 82). Através dessas reflexões José expõe seus sentimentos em relação ao mundo, em relação à vida. $E$ assim, é construída uma ideia de mundo através dos olhos de José. A sua subjetividade é usada para transmitir as sensações e o comportamento de um homem que vive limitado, censurado, violentado dia após dia sem conseguir escapar, pois o sofrimento chega por todos os lados.

\section{Conclusão}

José, a "América Latíndia", Rosa, Átila e todos os demais personagens funcionam como metáforas de situações reais, e assim, o autor consegue - tal como sugere ao lembrar as palavras de Erico Verissimo - "[...] acender um fósforo para iluminar um trecho da realidade" (Brandão apud Naxara; Vieira, 2011, p. 220). Nesse sentido, Zero é um romance que surge da resistência de Ignácio Loyola Brandão a ficar calado. Sua ação de transfigurar esteticamente o material jornalístico censurado, que acumulou ao longo de nove anos, tinha o objetivo de não deixar cair no esquecimento o que acontecia no Brasil nos períodos violentos da ditadura. Um posicionamento ético do autor diante do contexto social no qual estava inserido, uma forma de "iluminar" e fazer ouvir o que era silêncio.

\section{Referências}


ADORNO, Theodor W. Posição do narrador no romance contemporâneo. In: Notas de Literatura I. Tradução Jorge deAlmeida. São Paulo: Duas Cidades, 2003, p. 55-63.

AUERBACH, Erich. Mimesis: a representação da realidade na cultura ocidental. São Paulo: Editora Perspectiva, 1971.

BRANDÃO, Ignácio de Loyola. Zero. São Paulo: Global, 2001.

COSSON, Rildo. Romance reportagem: o gênero. São Paulo: Editora Universidade de Brasília, 2001.

GAGNEBIN, Janine. Verdade e memória do passado. Projeto História. São Paulo, n. 17, 1998, p. 213-221.

SMITH, Anne-Marie. Um acordo forçado: o consentimento da imprensa à censura no Brasil. Rio de Janeiro: Editora FGV, 2000.

SUSSEKIND, Flora. Literatura e vida literária: polêmicas, diários e retratos. Belo Horizonte: Editora UFSM, 2004.

UMBACH, Rosani Ketzer; CALEGARI, Lizandro Carlos (Org.). Estética e política na produção cultural: as memórias da repressão. Santa Maria: Editora UFSM, 2011.

VIEIRA, Vera Lúcia Silva; NAXARA, Regina Capelari. Entre a literatura, a história e a memória: entrevista com Ignácio Loyola Brandão. ArtCultura: Revista do Instituto de História da Universidade Federal de Uberlândia, v. 13, n. 22, p. 207-224, jan.-jun. 2011. 